Review Article

\title{
Informed consent in orthopaedic cases
}

\author{
Satvik N. Pai* \\ Department of Orthopaedic Surgery, Sri Ramachandra Medical College and Research Institute, Chennai, India
}

Received: 29 April 2021

Revised: 29 May 2021

Accepted: 01 June 2021

\section{*Correspondence:}

Dr. Satvik N Pai,

E-mail: satvik.pai@gmail.com

Copyright: ( $)$ the author(s), publisher and licensee Medip Academy. This is an open-access article distributed under the terms of the Creative Commons Attribution Non-Commercial License, which permits unrestricted non-commercial use, distribution, and reproduction in any medium, provided the original work is properly cited.

\begin{abstract}
Informed consent is an exercise to provide patients with adequate information before undergoing a medical procedure. Orthopaedic surgeons need to be aware of all aspects of informed consent and also certain modifications it requires as per the diagnosis/procedure planned. Extensive literature was reviewed regarding informed consent in orthopaedic cases. Medico-legal verdicts relating to orthopaedic cases where the informed consent played a vital part were analysed in detail. Specific orthopaedic cases and the common complications occurring after them were also analysed.
\end{abstract}

Keywords: Informed consent, Orthopaedic surgery, Complications, Litigation, Medico-legal

\section{INTRODUCTION}

Informed consent is an exercise which was designed to protect the rights of the patients and provide them with adequate information before undergoing a medical procedure. ${ }^{1}$ Its importance has risen significantly in the past few decades with it being the crux of several law suits. It is often the first area of interest for lawyers and insurers when a medico-legal malpractice suite is concerned. ${ }^{2}$ Hence, it is vital for medical professionals to be aware of all aspects related to informed consent. Orthopaedics surgeons deal with certain unique aspects in the field of medicine and are a higher risk to face malpractice suites than many other specialities in medicine. However, there is a lack of formal training in the curriculum regarding the exercise and documentation of informed consent. The purpose of this review was to provide a concise overview regarding informed consent in orthopaedic cases and formulate a guide for the points to be included in an informed consent in an orthopaedic case. Extensive literature was reviewed regarding informed consent in orthopaedic cases. Medico-legal verdicts relating to orthopaedic cases where the informed consent played a vital part were analysed in detail. Specific orthopaedic cases and the common complications occurring after them were also analysed. Also, literature regarding complications occurring after specific orthopaedic cases and medico legal cases regarding it were reviewed.

\section{DISCUSSION}

Informed consent is a consent obtained from the patient after the patient has been explained about their diagnosis, the treatment options available, pros and cons of each of those options, the recommendation of the doctor, and the possible complications that could occur as a result of performing said procedure. It ensures that the patient's right to choose what is being done to their own body is protected. It is also a vital document in any medico-legal proceeding. It has been the basis of various claims by patients alleging a lack of sufficient communication from the treating team prior to a procedure, but has also been used in the defence by treating doctors for documented proof of sufficient communication of risk and adequate understanding by the patient prior to the procedure regarding the possible complications arising from it. ${ }^{3}$ Thus it should not be viewed by medical professionals merely as s surplus formality of documentation, rather as a part of 
our duty towards the rights of the patient and a safeguard that comes to our aid in case of an untoward outcome. Orthopaedic surgeons deal with certain conditions which warrant a unique informed consent. The informed consent has to vary depending on the diagnosis, the procedure planned and also the prevailing circumstances at the time. There is however no real guide as to how this should be prepared. After extensive review of literature on the subject, a summary of essential points that should be included in the informed consent, with certain unique points depending on the condition being dealt with.

\section{In all cases}

Name, age and sex of the patient; hospital ID of the patient/identification marks if hospital ID not available; diagnosis- which include the side. It is preferable to also provide a grading/staging/classification of the condition using a system which is widely accepted across the world; procedure that is planned. It should include the site, side of the limb/body.4 Should include all the sub-procedures involved. If the decision on a procedure is to be taken intraoperatively depending on the intra-operative findings, the name of such procedure should also be included in the procedure name with a $+/$ - preceding it; name of the chief operating surgeon; date of the surgery; possible complications of the procedure- to enlist at least 3 of the most commonly arising complications of the procedure, along with 2 chronic, grave complications of the procedure. Should also mention if the possibility of another procedure may be required for the condition at a later date; signature of the patient with the date of attaining consent; signature of a witness/attender of the patient which should preferably be a family member of the patient, the individuals name, relationship to the patient should also be mentioned, along with the date of attaining consent; signature and name of the chief operating surgeon; signature and name of the doctor who has counselled the patient and attender regarding the condition and procedure, if it is different from the chief operating surgeon.

\section{Language}

It is ideal for the consent to be written in the language that the patient best understands. ${ }^{5}$ If that is not possible, it should be mentioned that the informed for the consent has been provided in the language the patient understands well. It is advisable to even mention which specific language the communication was in, and if a translator was used, then it is recommended to even include the name of the translator present for the communication. The consent should include simple language, avoiding the use of complicated terms as far as possible. The use of the medical terms should be done only where necessary. It is essential that the consent be legible, and a typed (printed) consent is also accepted. In a hand written consent, it is advisable to use capital letters for the diagnosis, procedure and complications.

\section{Surrogate consent}

For any patient under the age of 18 years, it is necessary to obtain informed consent from the parent/guardian. If the patient is unable to sign for the informed consent owing to an injury to the dominant upper limb, however the patient is in a state to comprehend the information being provided, then a thumb impression of the non-dominant hand is to be obtained in place of the signature. If the patient is unconscious or not in a state of mind to comprehend the information being provided, then it is necessary to obtain surrogate consent from the attender of the patient, preferable a family member of the patient. The name of the individual providing surrogate consent, and the relationship to the patient should be documented.

\section{Anaesthesia}

Consent for anaesthesia should be taken separately. It is should be taken after explaining the need for anaesthesia, the mode and route of anaesthesia, and also the possible complications of anaesthesia. The signature of the anaesthetist is also required.

\section{Fractures}

Due to the high variability in fracture patterns and treatment options varying not only between the choice of surgery, but also the choice of implants and choice of incision. As far as possible these details should be provided to the patient. The reasoning for the choices should also be mentioned. ${ }^{6}$ Complications listed should include bleeding, surgical site infection and neurological injury. Non-union, malunion should be included if appropriate. Also a good practice to include the approximate period of immobilisation that may be required following the procedure. Decreased range of movements, secondary arthritis should be mentioned for severe intra-articular fractures. For open fractures, the classification based on Gustilo-Anderson classification system should be mentioned. For high energy trauma causing fractures in forearm, thigh or leg, compartment syndrome should be mentioned in the complications as these areas are more prone for it. ${ }^{7}$

\section{Arthroplasty}

Preferable to include the company and model name of the implant planned to be used.8 Complications listed should include: bleeding, surgical site infection, neurological injury, deep vein thrombosis and pulmonary embolism. Decreased range of movement, chances of persistence of pain, and aseptic loosening of the implant should also be included. ${ }^{9}$ The lifespan of the implant- with most current implants having a life span of 15-20 years should be mentioned. 


\section{Amputation}

The specific indication for the amputation should be clearly mentioned. ${ }^{10}$ It is also important to mention the level of the amputation. The need for prosthesis/walking aid following surgery should be mentioned. Complications listed should include phantom limb pain, wound infection, neuroma and deep vein thrombosis. For patients with crush injury of a limb, it is advisable to include the Mangled extremity severity score (MESS).

Table 1: Complications to be listed in informed consent for specific orthopaedic cases.

\begin{tabular}{|c|c|}
\hline Diagnosis/Procedure & $\begin{array}{l}\text { Informed consent to include } \\
\text { following complications }\end{array}$ \\
\hline Fractures & $\begin{array}{l}\text { Surgical site infection } \\
\text { Bleeding } \\
\text { Neurological injury } \\
\text { Malunion } \\
\text { Non-union } \\
\text { Decreased Range of } \\
\text { movement, Secondary } \\
\text { Arthritis (for intra-articular } \\
\text { fractures) }\end{array}$ \\
\hline Arthroplasty & $\begin{array}{l}\text { Surgical site infection } \\
\text { Bleeding } \\
\text { Neurological injury } \\
\text { Deep vein thrombosis, } \\
\text { pulmonary embolism } \\
\text { Decreased range of movement } \\
\text { Persistence of pain } \\
\text { Aseptic loosening }\end{array}$ \\
\hline Amputation & $\begin{array}{l}\text { Phantom limb pain } \\
\text { Wound infection } \\
\text { Neuroma formation } \\
\text { Deep vein thrombosis }\end{array}$ \\
\hline Tumours & Recurrence \\
\hline Paediatric cases & $\begin{array}{l}\text { Alteration in bone growth } \\
\text { Limb length discrepancy }\end{array}$ \\
\hline Spine cases & $\begin{array}{l}\text { Surgical site infection } \\
\text { Deep vein thrombosis, } \\
\text { Paralysis, } \\
\text { Dural tear } \\
\text { Leakage of cerebrospinal } \\
\text { fluid, } \\
\text { Bowel/bladder incontinence }\end{array}$ \\
\hline
\end{tabular}

\section{Tumours}

If the Histopathological confirmation of the tumour is not available prior to surgery, it is important to also mention the differential diagnosis along with the provisional diagnosis. It is imperative to mention whether the procedure being performed is diagnostic/therapeutic or both. The need for confirmatory tests, especially a Histopathological confirmation, along with investigations to assess possible local/systemic spread of the disease is to be highlighted. The various treatment modalities should be mentioned with the pros and cons of each. All the individuals included in the decision making for the treatment plan to be followed are to be mentioned. The chance of recurrence should also be clearly explained.

\section{Paediatric cases}

Important to include the possibility of alteration in growth of the bone, limb-length discrepancy to be mentioned if the condition/procedure may cause damage to the growth plate.

\section{Spine}

Complications listed should include surgical site infection, deep vein thrombosis, paralysis, dural tear, leakage of cerebrospinal fluid, bowel/bladder incontinence. It is also vital to document the neurological status prior to the surgery.

\section{Non-operative treatment}

For a condition which has an option of being treated operatively, a decision is made to treat it non-operatively, it a good practice to obtain an informed consent of the patient even in such an instance. The pros and cons of nonoperative management, individuals involved in the decision making are also to be mentioned. ${ }^{11}$ The need for follow up and possibility of requirement of surgery in the future are also to be included.

\section{ICU care}

The possibility of requirement of care in the Intensive Care Unit (ICU) should be mentioned and explained to patients and attenders. This is especially true for elderly patients, patients with multiple co-morbidities, patients undergoing multiple procedures and polytrauma patients.

\section{CONCLUSION}

While a medical professional can give valuable advice and recommendation based on his/her knowledge and inexperience, eventually it is the patient who determines what is to be done to their body. Thus informed consent is a vital document that is often the crux of various medicolegal cases. It is important for all orthopaedic surgeons to be aware of the documentation of the informed consent and all the points to be included in it. It is also essential to know the specific complications to be mentioned for a procedure. Informed consent is recommended even in patients for whom decisions of non-operative management has been made.

\section{Funding: No funding sources \\ Conflict of interest: None declared \\ Ethical approval: Not required}

\section{REFERENCES}

1. Bhattacharyya T, Yeon H, Harris MB. The medicallegal aspects of informed consent in orthopaedic 
surgery. J Bone Joint Surg Am. 2005;87(11):2395400.

2. Gould MT, Langworthy MJ, Santore R, Provencher MT. An analysis of orthopaedic liability in the acute care setting. Clin Orthop Relat Res. 2003;(407):5966.

3. Grauberger J, Kerezoudis P, Choudhry AJ. Allegations of Failure to Obtain Informed Consent in Spinal Surgery Medical Malpractice Claims. JAMA Surg. 2017;152(6):e170544.

4. Furey A, Stone C, Martin R. Preoperative signing of the incision site in orthopaedic surgery in Canada. $\mathrm{J}$ Bone Joint Surg Am. 2002;84(6):1066-8.

5. Baldwin DC Jr, Adamson TE, Self DJ, Sheehan TJ, Oppenberg AA. Moral reasoning and malpractice. A pilot study of orthopedic surgeons. Am J Orthop (Belle Mead NJ). 1996;25(7):481-4.

6. Gwynne A, Barber P, Tavener F. A review of 105 negligence claims against accident and emergency departments. J Accid Emerg Med. 1997;14(4):243-5.
7. Bhattacharyya T, Vrahas MS. The medical-legal aspects of compartment syndrome. J Bone Joint Surg Am. 2004;86(4):864-8.

8. Pai S. Medico-Legal Issues Related to Hip and Knee Arthroplasty: A Literature Review Including the Indian Scenario [published online ahead of print, 2021 Mar 30]. Indian J Orthop. 2021;1-9.

9. Attarian DE, Vail TP. Medicolegal aspects of hip and knee arthroplasty. Clinical Orthopaedics and Related Research. 2005;(433):72-6.

10. Klimo GF, Daum WJ, Brinker MR, McGuire E, Elliott MN. Orthopedic medical malpractice: an attorney's perspective. Am J Orthop (Belle Mead NJ). 2000;29(2):93-7.

11. Higgins, Laurence D. Clinical Orthopaedics and Related Research (1976-2007). 2005;443:58-64.

Cite this article as: Pai SN. Informed consent in orthopaedic cases. Int J Res Orthop 2021;7:868-71. 